\title{
A Simple Model for Determining Evaporation from High-Latitude Upland Sites
}

\author{
Wayne R. Rouse and Robert B. Stewart \\ Dept. of Geography, McMaster University, IIamilton, Canada
}

(Manuscript received 8 March 1972, in revised form 20 June 1972)

\begin{abstract}
ABSTRAC $T$
Energy-budget calculations and equilibrium model estimates of evaporation from a lichen-dominated upland site in the Hudson Bay lowlands are presented. The energy-budget calculations reveal that the lichen surface is relatively resistant to evaporation with an average of only $54 \%$ of the daily net radiation being utilized in the evaporative process. Equilibrium model estimates of evaporation consistently overestimate actual evaporation by 5 and $8 \%$ for hourly values and daily totals, respectively. A simple model, a function of the equilibrium model, is derived from a comparison of actual and equilibrium evaporation. The only inputs required for the model are net radiation, soil heat flow and screen temperatures. Tests of the model indicate that it will predict actual evaporation within $5 \%$ and that it can probably be applied to any high-latitude surface which exhibits a relatively large diffusive resistance to evaporation.
\end{abstract}

\section{Introduction}

High-latitude upland sites in northern Canada present a unique environment with respect to evaporation. They are typically dominated by non-transpiring ground lichen cover, mixed ground lichen and widelyspaced conifers, and lower order vascular plants. These surface covers all exhibit a diffusive resistance to the efficient movement of water vapor from the moisture source to the atmospheric sink. They are important both in terms of high-latitude ecology and in terms of high-latitude energy budgets since they comprise a significant portion of the subarctic and tundra landscape. For example, in northern Quebec approximately $600,000 \mathrm{~km}^{2}$ of the area is composed of lichen woodland (Hare, 1959) and in northern Saskatchewan lichen woodland makes up about $100,000 \mathrm{~km}^{2}$ of land area (Pruitt, 1959). Immediately beyond the tree line in most of Canada there are belts and patches of lichen heath. These are particularly prominent adjacent to the Hudson Bay coastline.

Rouse and Kershaw (1971) carried out energy-budget measurements in spruce-lichen woodland in northern Ontario and found that in spite of readily available soil moisture the evaporative flux comprised only around $60 \%$ of the available radiant energy, thus suggesting substantial resistance to evaporation.

Because of the inaccessibility of many of the subarctic and tundra regions and because of the large area involved, a simple and accurate model for estimating evaporation is desirable. One of the simplest models is the equilibrium model presented by Slatyer and McIlroy (1961).

The model as originally presented was considered applicable only under conditions of a saturated atmo- sphere. Further developments, however, have revealed that the model is applicable, also in non-saturated conditions (Denmead and McIlroy, 1970). Wilson and Rouse (1972) found that the equilibrium model performed well over a moderately dry surface exhibiting a relatively high resistance to evaporation, and that it could be expressed simply as a function of air temperature and available radiant energy.

It is apparent that the equilibrium model or some function of the equilibrium model might be applied to estimate the evaporation for resistant subarctic and tundra surfaces. This hypothesis is tested by comparing equilibrium model estimates of evaporation to corresponding values of actual evaporation determined from the energy budget (Bowen ratio) approach. The research was conducted over a lichen-covered raised beach system in the Hudson Bay lowlands of northern Ontario during July and August, 1971.

\section{Energy budget and equilibrium evaporation}

The energy budget solution as presented by Bowen (1926) can be expressed in the form

$$
\begin{aligned}
L E=\frac{R_{n}-G}{1+H / L E}= & \frac{R_{n}-G}{1+\beta} \\
& =\left(R_{n}-G\right)\left[1-\left(\frac{\gamma}{s+\gamma}\right)\left(\frac{\Delta T}{\Delta T_{w}}\right)\right],
\end{aligned}
$$

where $L E$ is the evaporative heat flux; $R_{n}$ and $G$ are net radiation and soil heat flow, respectively; $H$ is the sensible heat flux; $\beta=H / L E$ is the Bowen ratio; $\gamma$ is the psychrometer constant; $S$ is the slope of the saturation vapor pressure-temperature curve at mean wet bulb 


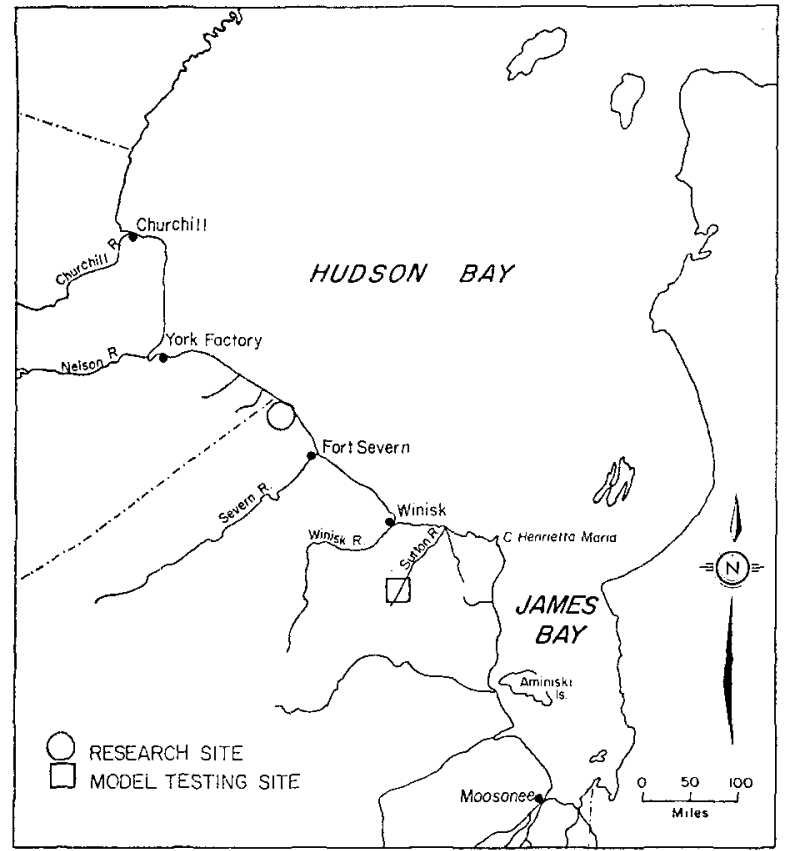

FIG. 1. Location of research site and model testing site. temperature; and $\Delta T$ and $\Delta T_{w}$ are the vertical gradients of dry bulb and wet bulb temperatures, respectively.

Eq. (1) has proven to give an accurate determination of $L E$ in numerous experiments providing measurements are made within the boundary layer and the wet and dry bulb temperatures are measured with a high degree of accuracy.

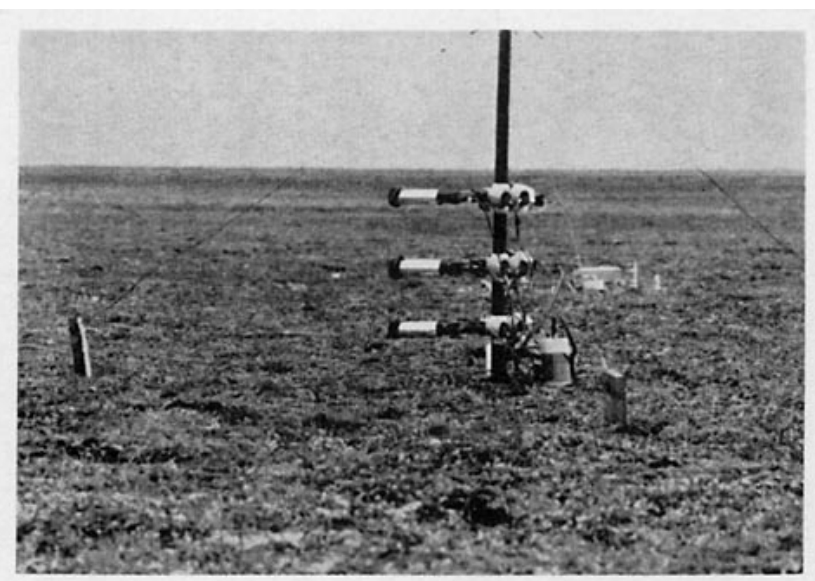

FIG, 2. Research site with the Bowen ratio mast.
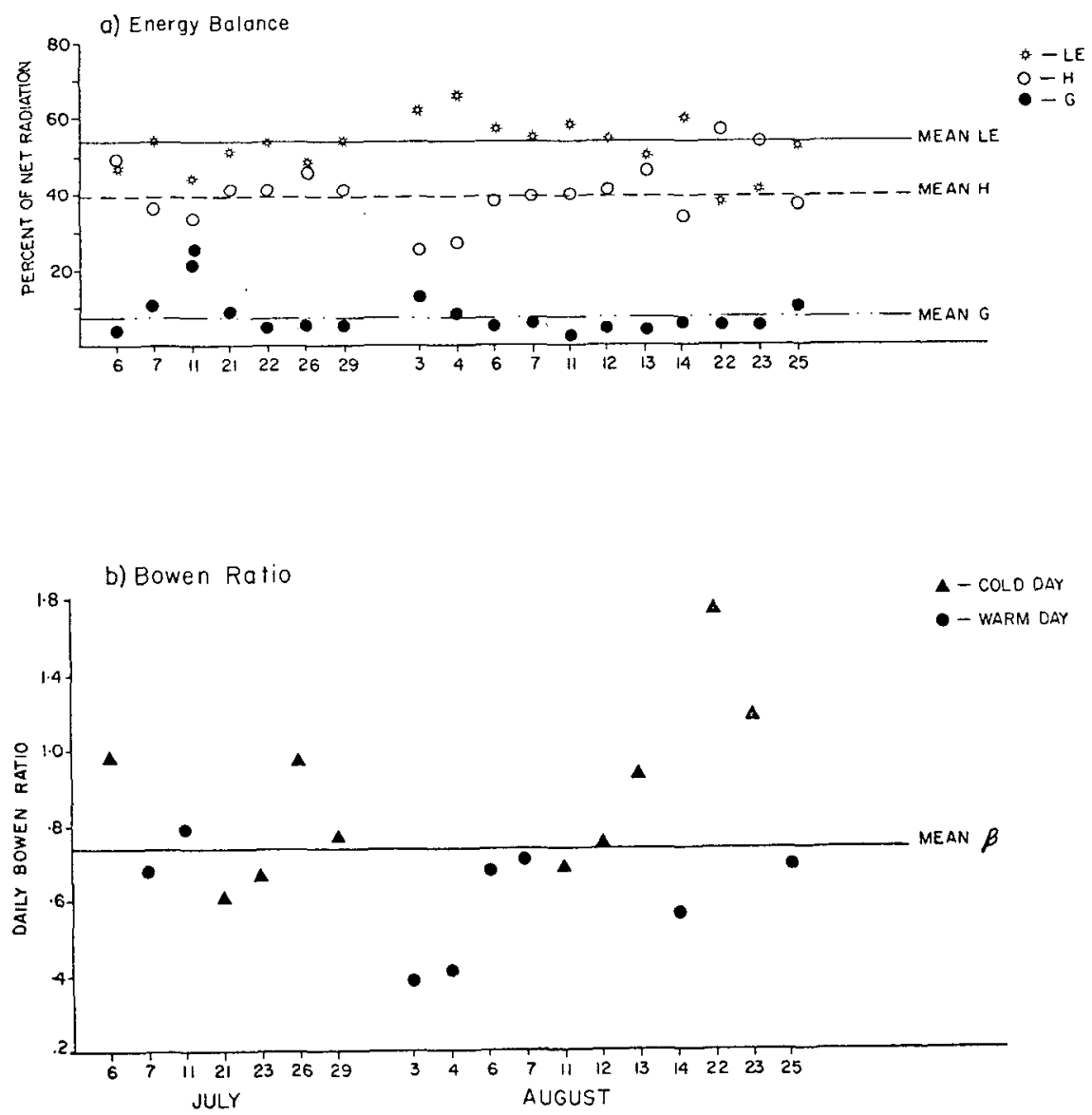

FIs. 3. Seasonal variations of the energy-balance components and Bowen ratio. 


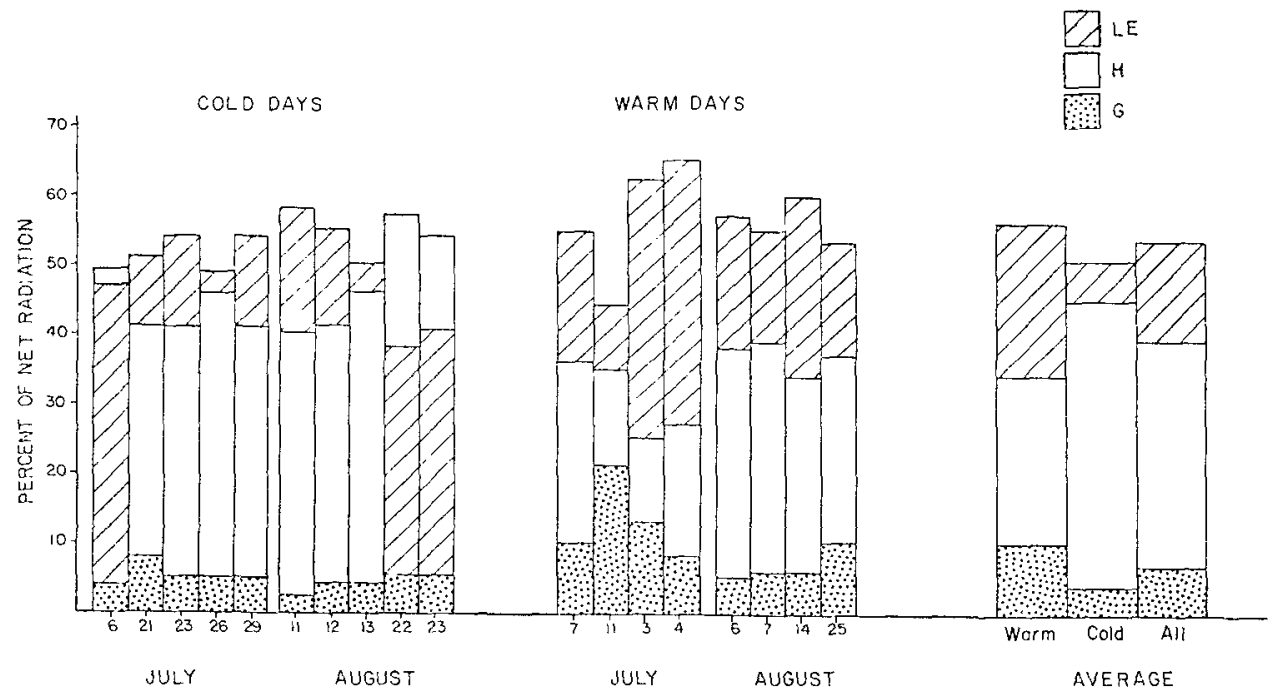

FiG. 4. Energy balance components for warm and cold days.

The theory of equilibrium model evaporation is developed in detail by Slatyer and McIlroy (1961) and Monteith (1965). The model is developed from the combination equation

$$
L E=\frac{S}{S+\gamma}\left(R_{n}-G\right)+\frac{\rho C_{p}}{r_{a}}\left(D_{z}-D_{0}\right)
$$

where $\rho$ is air density; $C_{p}$ is the specific heat of air at constant pressure; $D_{z}$ and $D_{0}$ are the wet bulb depressions in the overlying air and at the surface, respectively; and $r_{a}$ is the aerodynamic resistance to the diffusion of water vapor.

The first term on the right-hand side of Eq. (2) represents the contribution to evaporation made by the available radiant energy, whereas the second represents the atmospheric influence. In the case of a saturated atmosphere when $D_{z}-D_{0}=0$, the atmospheric term disappears from (2) to give

$$
L E_{E_{Q}}=\left(S^{\prime} S+\gamma\right)\left(R_{n}-G\right)
$$

which is the equilibrium model for evaporation as originally presented by Slatyer and McIlroy (1961), where $L E_{E Q}$ refers to equilibrium evaporation. Although originally defined for a standard atmosphere, Eq. (3) has been shown also to apply in a non-saturated atmosphere when the resistance to evaporation grows large. This eliminates the last term in Eq. (2). Moreover, $(S / S+\gamma)$ can be expressed simply as a linear function of screen temperature as shown by Wilson and Rouse (1972) which gives Eq. (3) the welcomed advantage of simplicity.

\section{Experimental methods}

a. Site

The research was conducted during July and August, 1971, near the Hudson Bay coastline in northern
Ontario (Fig. 1). Observations were made on a flat raised beach ridge illustrated in Fig. 2, located $15 \mathrm{mi}$ north of the treeline and $\sim 1 \mathrm{mi}$ inland from the coast. The site approaches an infinitely homogeneous plain as is evident in Fig. 2, and presents no problems in boundary-layer adjustment.

The vegetation in the vicinity of the site was typical of upland tundra vegetation and included lichens, mosses and a few stunted shrubs. The ground lichen cover included Cetraria islandica, C. nivalis, C. cucullata, Alectoria ochroleuca, while the vascular plants were represented by Vaccinium uliginosum, Dryas integrifolia, Rhododendron lapponicum. Lichen vegetation dominated the site as it did for all the upland areas and formed a mat averaging $6 \mathrm{~cm}$ thick.

The vegetation cover was underlain by a sandy soil varying from fine to coarse sand. The sands were very porous to rainwater and no surface runoff was evident. At lower depths between 50 and $100 \mathrm{~cm}$ the soils remained at field capacity throughout the summer period indicating that only the surface soil layers underwent active moisture exchange with the atmosphere.

\section{b. Measurements}

Evaluation of the energy balance by Eq. (1) requires the measurement of net radiation, soil heat flux, and dry and wet bulb temperature gradients above the surface. Net radiation was measured with a shielded net radiometer (Swissteco, Type S-1) mounted $1 \mathrm{~m}$ above the surface. Soil heat flux was calculated as the sum of the measured flux at $5 \mathrm{~cm}$ depth and the calculated flux divergence between $5 \mathrm{~cm}$ and the surface using a procedure similar to that described by Fuchs and Tanner (1968). Five-junction thermopile units described by Wilson and Rouse (1972) were used to measure $\Delta T$ and $\Delta T_{w}$ at 25,50 and $75 \mathrm{~cm}$ above the surface. $L E$ was determined hourly from Bowen ratio 


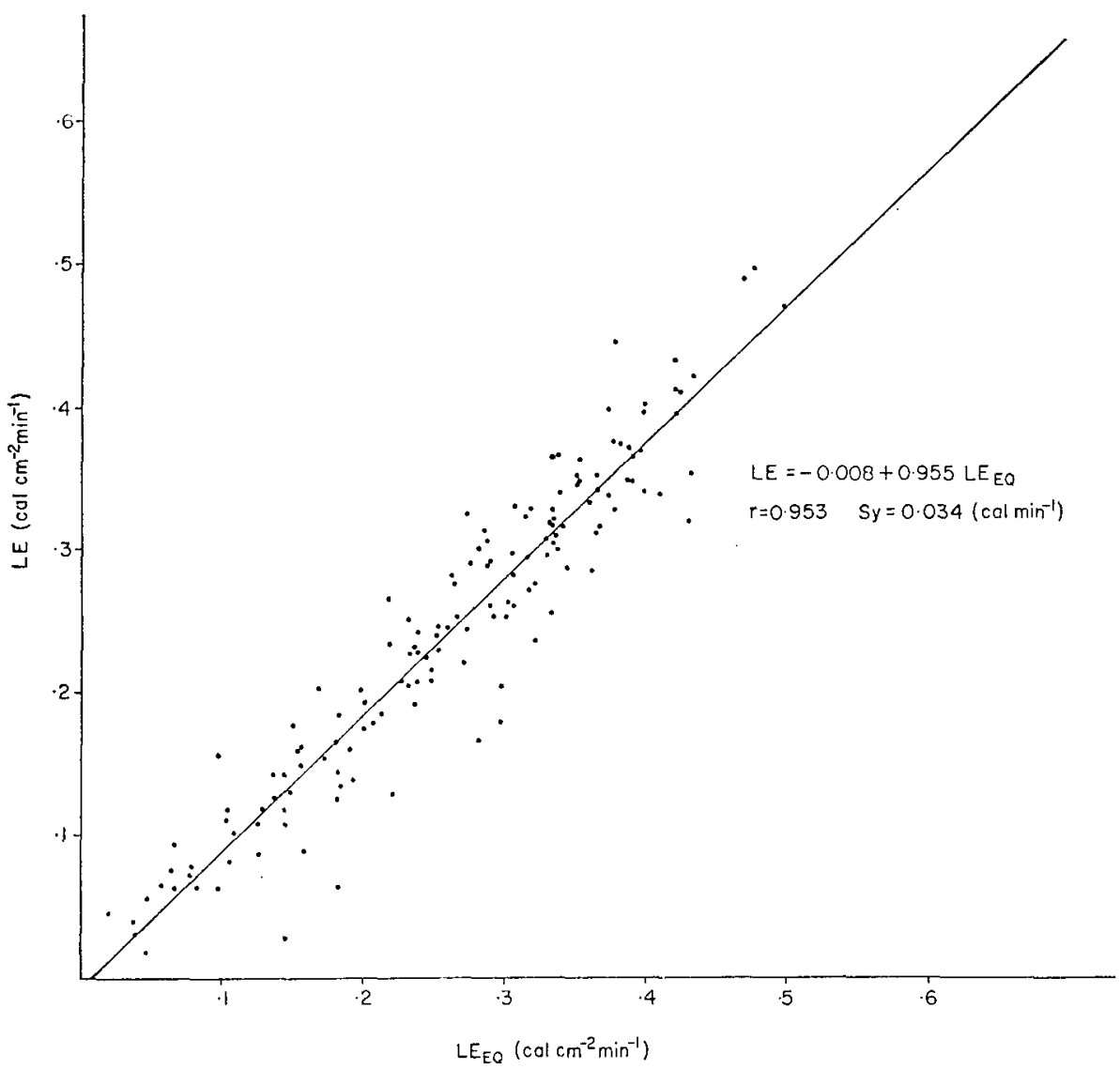

FIg. 5. Seasonal comparison of average hourly $L E$ to $L E_{H Q}$.

TABLE 1. Daily meteorological and surface soil moisture data.

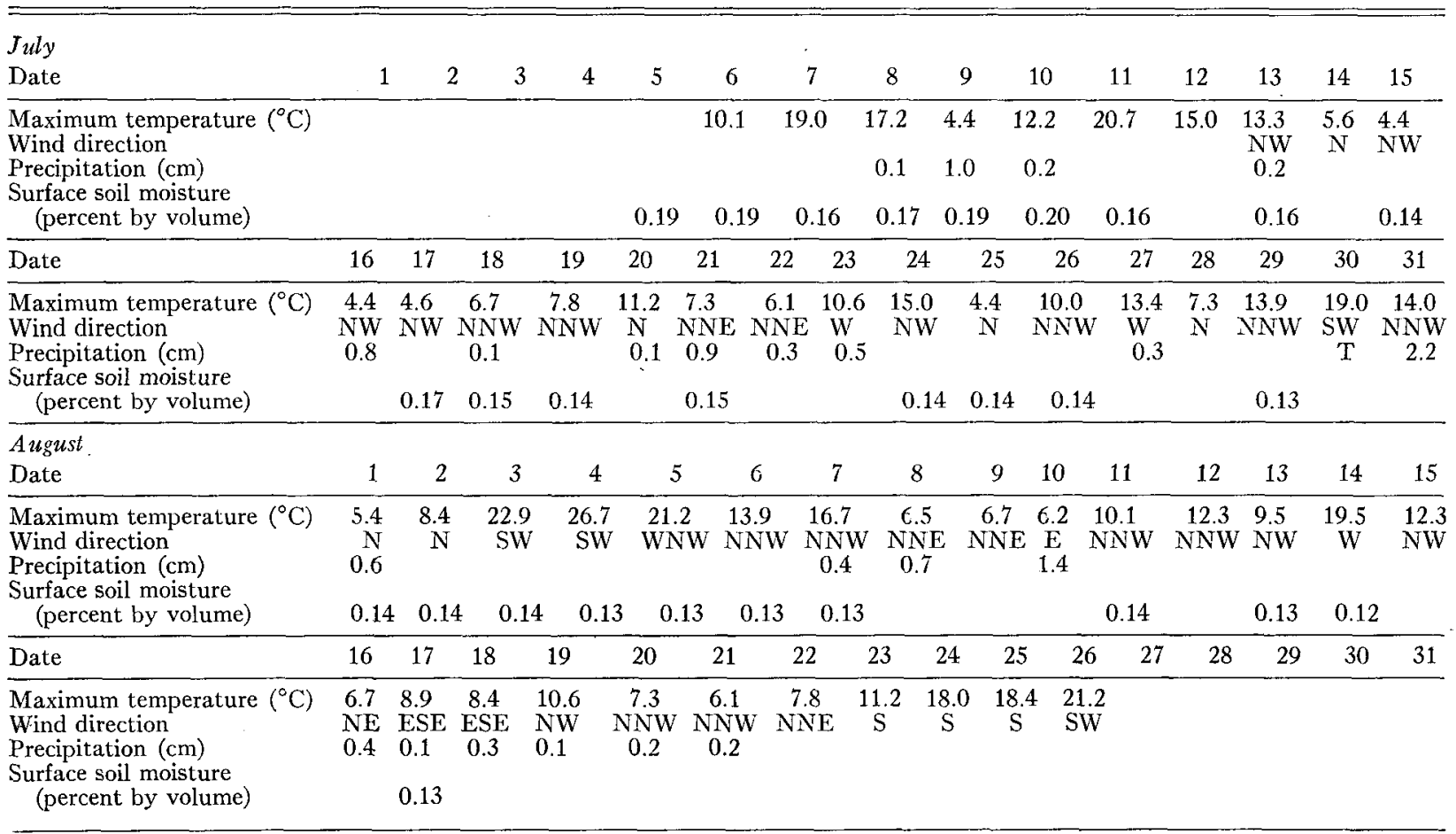




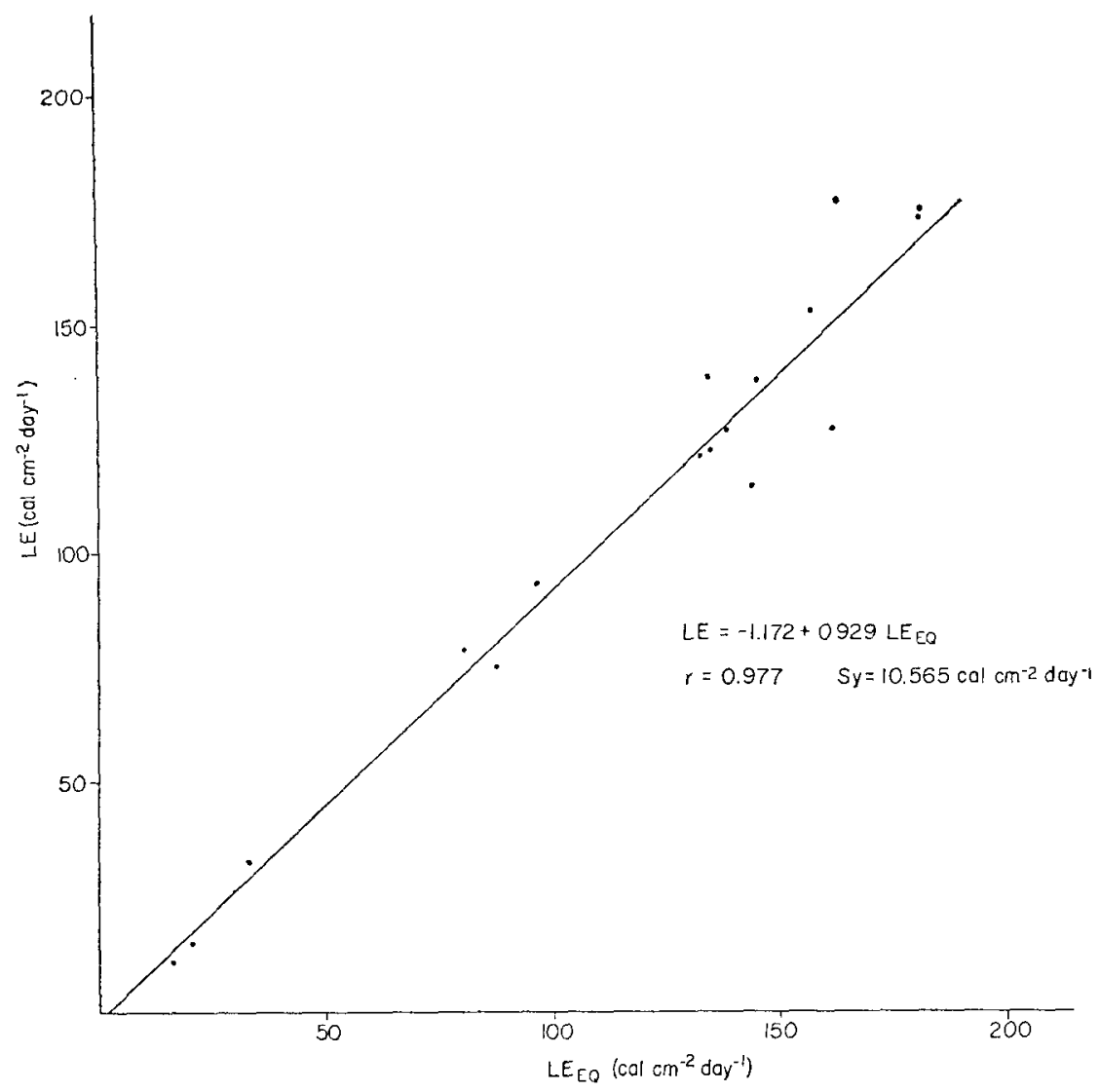

Iig. 6. Comparison of daily LE to $L E_{E Q}$.

calculations obtained for the three air levels: 25-50, $50-75$ and $25-75 \mathrm{~cm}$, with daily totals calculated as the sum of the hourly values. Daily values of the Bowen ratio were determined by dividing the daily totals of $H$ by $L E$.

In addition, wind direction, precipitation, and screenlevel air temperatures were measured.

\section{Results}

\section{a. Energy budget}

Daily values of the energy balance components, each presented as a percentage of $R_{n}$ during clear sky conditions, are shown in Fig. 3a. The components remained fairly constant throughout the study period and the averages of the values of $L E, H$ and $G$ were 54 , 39 and $7 \%$ of $R_{n}$, respectively.

Average daily Bowen ratios are plotted in Fig. 3b. The mean value for $\beta$ was 0.73 for the 19 days of measurement with maximum and minimum values of 1.78 on 22 August and 0.39 on 3 August. The generally high $\beta$ values indicate that the lichen-dominated surface is highly resistant to evaporation with the sensible heat component comprising a significant proportion of the available radiant energy.
A substantial temperature influence on the magnitude of the energy balance parameters was found. Table 1 shows that the maximum temperature varied significantly with changing wind direction. If the winds are divided into two primarily directional groups--northerly winds, which include all winds from east to north to west, and southerly winds, from east to south to westit is found that temperatures rarely exceeded $15 \mathrm{C}$ with northerly winds and rarely fell below $15 \mathrm{C}$ with southerly winds. The data were divided, therefore, into cold days $\left(T_{\max }<15 \mathrm{C}\right)$ and warm days $\left(T_{\max }>15 \mathrm{C}\right)$.

Fig. 4 shows the energy-balance components for warm and cold days, $L E$ on warm days exceeds the cold day value by only $5 \%$ whereas $H$ is $11 \%$ lower on the warm days. As $H$ grows larger on the cold days, $G$ grows small. The opposite effect is observed for warm days. With a warm atmosphere more energy is utilized in $G$, since the soil temperature gradient, $\Delta T_{s} / \Delta Z$, is larger relative to the atmospheric temperature gradient, $\Delta T / \Delta Z$, than for a colder atmosphere.

\section{b. Equilibrium evaporation}

$L E$ was compared to $L E_{E Q}$ for both hourly and daily totals. The 148 hourly values examined pertain exclusively to a non-saturated atmosphere. Fig. 5 shows $L E$ 


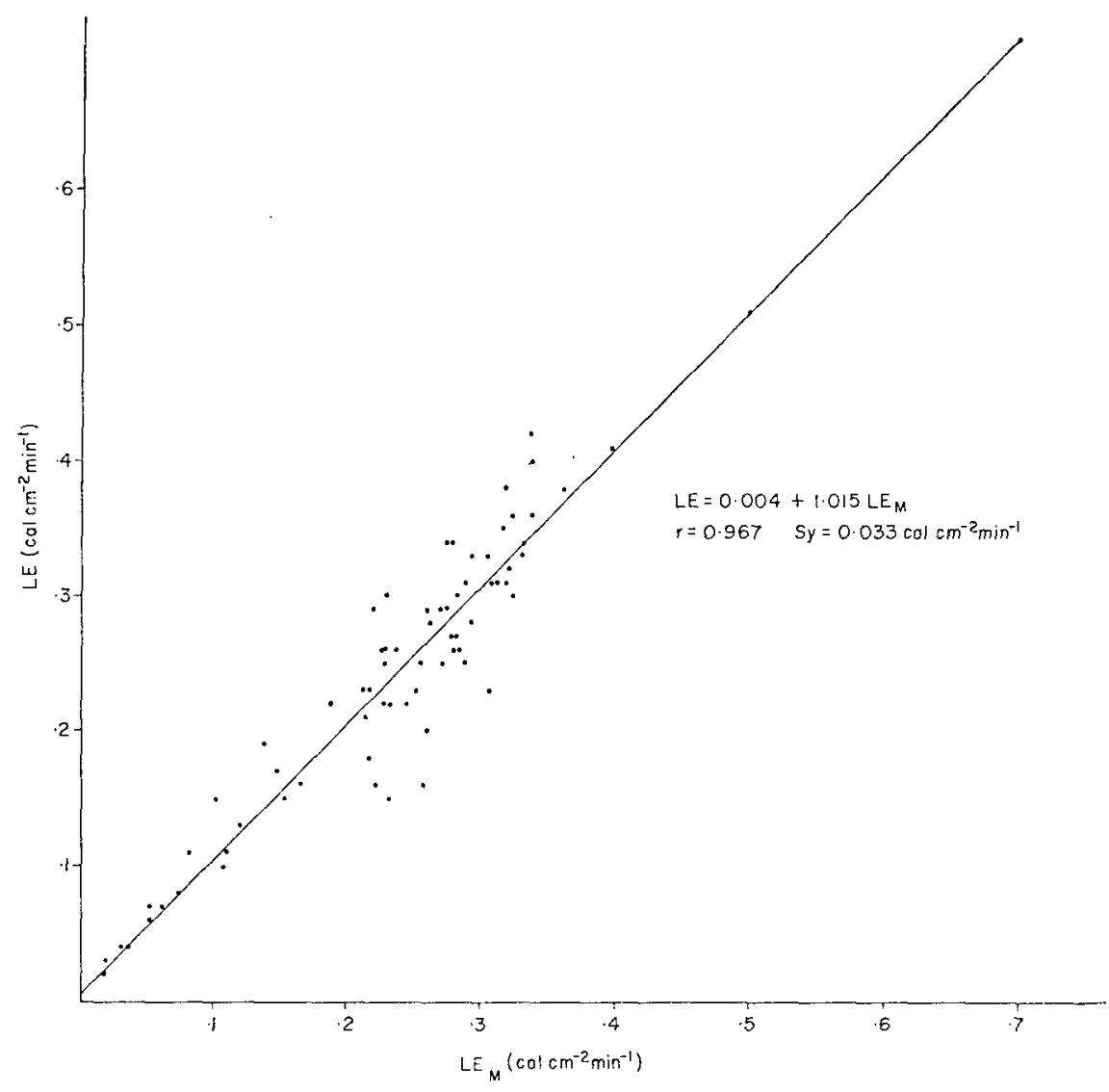

FIG. 7. Hourly relationships between $L E$ and $L E_{M}$ for Hawley Lake.

plotted as a function $L E_{E Q}$. The linear relationship which plots hourly averages of the latent heat flux (cal $\mathrm{cm}^{-2} \mathrm{~min}^{-1}$ ) gives

$$
\left.\begin{array}{rl}
L E & =-0.008+0.955 L E_{E Q} \\
r & =0.953, S_{y}=0.034 \mathrm{cal} \mathrm{cm}^{-2} \mathrm{~min}^{-1}
\end{array}\right\},
$$

where $r$ and $S_{y}$ are the correlation coefficient and standard error, respectively. Eq. (4) shows that $L E_{E Q}$ consistently overestimates $L E$ by about $5 \%$. Daily totals of $L E$ vs $L E_{E Q}$ are shown in Fig. 6. The daily totals of $L E$ are overestimated by $8 \%$.

\section{c. Conditions in which the equilibrium model applies}

In theory the equilibrium model should apply when the second term on the right-hand side of $\mathrm{Eq}$. (2) approaches zero. This will occur when $D_{z} \approx D_{0}$, when $r_{a}$ grows large, or when both of these conditions occur. In this study $\Delta D$ between the 25 and $75 \mathrm{~cm}$ heights was negative, averaged $0.6 \mathrm{C}$, and varied between 0.2 and $1.0 \mathrm{C}$. If $\Delta D_{25-75}$ indicates $\Delta D$ between the surface and overlying atmosphere, then $D_{z}$ never approached $D_{0}$. Therefore, it is evident that $\boldsymbol{r}_{a}$ must be large in order to reduce the second term on the right-hand side of Eq. (2) toward zero.
By definition $r_{a}$ refers to the resistance to diffusion of water vapor from the effective evaporating surface into the air. In the case of a non-transpiring lichen vegetation, the effective surface is not at the dry top of the canopy, but occurs near the moist canopy base. In a thick lichen mat wind speed decreases rapidly within the canopy and since $r_{a}$ is an inverse function of wind speed (Monteith, 1965) the diffusive resistance increases with depth in the canopy. The negative values of $D_{z}-D_{0}$ account for the equilibrium model overestimating actual evaporation.

\section{d. Significance of results}

The excellent relationship between $L E_{E Q}$ and $L E$ implies that a simple model based on the concept of the equilibrium model can be utilized to precisely estimate $L E$ as a function of temperature and radiant energy.

\section{Derivation and test of a simple evaporation model}

The $L E_{E Q}$ computation of evaporation as expressed in Eq. (4) and Fig. 4 explains $91 \%$ of $L E$ for hourly values. This is a good agreement when one considers the wide range of temperature and moisture conditions over which $L E_{E Q}$ was estimated. 


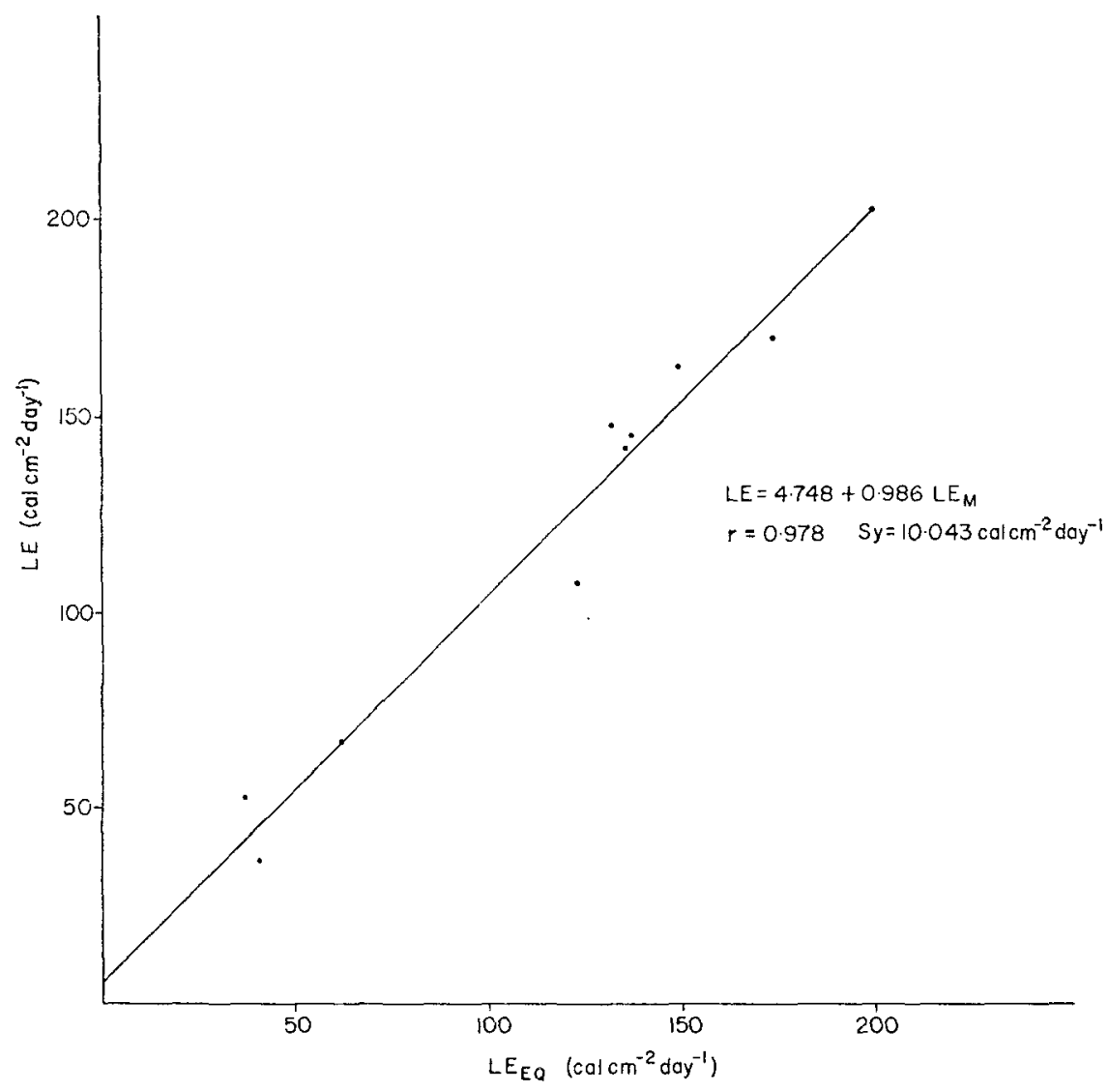

Fig. 8. Daily totals relationship between $L E$ and $L E_{M}$ for Hawley Lake.

Further simplification of Eq. (3) was indicated in the work of Wilson and Rouse (1972) who showed that $S /(S+\gamma)$ could be calculated as a linear function of temperature with a high degree of accuracy over a temperature range from 17 to $32 \mathrm{C}$, a range nearly equivalent to the "warm day" category used here. With the inclusion of a "cold day" temperature range to include all data in this study, $S /(S+\gamma)$ expressed as a linear function of hourly mean temperatures gives

$$
\left.\begin{array}{c}
S /(S+\gamma)=0.434+0.012 T \\
r=0.998, S_{y}=0.003 \mathrm{C}^{-1}
\end{array}\right\} .
$$

Eq. (5) is very similar in magnitude to that calculated by Wilson and Rouse. Substituting Eq. (5) into (4) gives

$$
L E=L E_{M}=(0.406+0.011 T)\left(R_{n}-G\right),
$$

where $L E_{M}$ is the prediction model by which $L E$ can be determined in cal cm $\mathrm{cmin}^{-1}$. Eq. (6) is readily converted for use in terms of hourly and daily totals.

To test the validity of (6) as a general model for estimating $L E$ over upland subarctic surfaces, $L E$ data gathered by Rouse and Kershaw (1971), who made energy-budget measurements at Hawley Lake, a site $200 \mathrm{mi}$ ESE of the present study site (Fig. 1), were used.
The two surface types which they considered were a natural lichen surface, composed almost entirely of Cladonia alpestris in a dense mat averaging $11 \mathrm{~cm}$ thick, and a previously burned lichen surface that was just beginning to be revegetated, but was still covered with the thick ash of the burned lichen. Temperature and available radiant energy varied from -0.3 to $24.0 \mathrm{C}$ and -0.012 to $0.690 \mathrm{cal} \mathrm{cm}^{-2} \mathrm{~min}^{-1}$, respectively.

Fig. 7 shows the relationship between hourly predicted values of $L E_{M}$ and measured values for both surfaces. The good agreement of the relationship is evident. For daily totals the agreement was even closer as shown in Fig. 8.

The good agreement of $L E$ estimates for the lichencovered and burned surfaces, as shown in Figs. 6 and 7 , is of significant importance. Previous discussion has revealed that the high surface resistance to evaporation is the prime reason for the equilibrium model applying for high-latitude upland sites. The successful testing of the model on the lichen and burned sites indicates that the diffusive resistances are of comparable magnitudes and that $L E_{M}$ should therefore be applicable over any tundra or subarctic land surface which displays a high resistance to evaporation. 


\section{Conclusion}

The simple evaporation model presented in this paper estimates actual evaporation within $5 \%$ for both hourly and daily totals for a high-latitude lichen-dominated upland site. The only necessary inputs to the model are net radiation, soil heat flux and screen temperature. Tests of the model suggest that evaporation can be estimated reliably for any high-latitude surface which exhibits a relatively large resistance to evaporation.

Acknowledgments. This research was supported by grants from the National Research Council of Canada, The National Geographic Society, Washington, D. C., and the McMaster University Research Board. The field research assistance of Dr. K. A. Kershaw, Miss Dorothy Van Eyk and Mr. Zdenko Kozlovic is gratefully acknowledged. We wish to thank Transair Midwest for allowing us the use of their Hudson Bay field camp as a research site.

\section{REFERENCES}

Bowen, I. S., 1926: The ratio of heat losses by conduction and by evaporation from any water surface. Phys. Rev., 27, 779-787.

Denmead, O. T., and I. C. McIlroy, 1970: Measurements of nonpotential evaporation from wheat. Agr. Meteor., 7, 285-302.

Fuchs, M., and C. B. Tanner, 1968: Calibration and field test of soil heat flux plates. Soil Sci. Soc. Amer. Proc., 32, 326-328.

Hare, F. K., 1959: A photo-reconnaissance survey of LabradorUngava. Can. Dept. Mines Tech. Surv., Geogr. Br., Memo. No. 6, $83 \mathrm{pp}$.

Monteith, J. L., 1965 : Evaporation and environment. Symp. Soc. Exp. Biol., 19, 205-234.

Pruitt, W. O., 1959: Snow as a factor in the ecology of caribou. Arctic, 12, 159-179.

Rouse, W. R., and K. A. Kershaw, 1971: The effects of burning on the heat and water regimes of lichen-dominated subarctic. surfaces. Arctic Alpine Res., 3, 291-304.

-- , and R. G. Wilson, 1972: A test of the potential accuracy of the water budget approach to estimating evapotranspiration. Agr. Meteor., 9, 421-446.

Slatyer, R. O., and I. C. McIlroy, 1961: Practical Microclimatology. CSIRO, Melbourne, $310 \mathrm{pp}$.

Wilson, R. G., and W. R. Rouse, 1972: Moisture and temperature limits of the equilibrium evapotranspiration model. J. Appl. Meteor., 11, 436-442. 